\title{
VULNERABILIDADE SOCIAL À LUZ DO ARTIGO 791-A DA CLT PÓS REFORMA TRABALHISTA.
}

\author{
Rafael Ribeiro Santos* \\ Eric Araújo Andrade Oliveira*
}

\section{RESUMO:}

O presente artigo tem por objetivo analisar o conceito de vulnerabilidade atualmente vivenciado no Direito do Trabalho, sobre o prisma do artigo 791-A da Consolidação das Leis Trabalhistas num cenário pós reforma. Investiga-se a ideia de vulnerabilidade para justificar a ampliação da proteção normativa própria do Direito do Trabalho. O método escolhido foi o lógico dedutivo e a pesquisa qualitativa. A partir da identificação de vulnerabilidades poderá o intérprete, em situações jurídicas complexas, aplicar a estrutura de proteção social jus trabalhista ou não.

Palavras-Chave: Vulnerabilidade; Proteção; Direito do Trabalho; Artigo 791-A; Reforma trabalhista

\section{SOCIAL VULNERABILITY IN LIGHT OF ARTICLE 791-A OF THE CLT AFTER LABOR REFORM.}

\begin{abstract}
:
This article aims to analyze the concept of vulnerability currently experienced in Labor Law, under the prism of Article 791-A of the Consolidation of Labor Laws in a post-reform scenario. The idea of vulnerability is investigated to justify the expansion of the normative protection of Labor Law. The chosen method was the logical deductive and the qualitative research. From the identification of vulnerabilities, the interpreter, in complex legal situations, can apply the social protection structure, whether labor law or not.
\end{abstract}

Key Words: Vulnerability; Protection; Labor Law; Article 791-A; Labor reform

\section{INTRODUÇÃO}

O presente artigo tem como objetivo compreender o conceito de vulnerabilidade social no contexto do atual Direito do Trabalho num cenário pós reforma trabalhista sob a luz do

\footnotetext{
* Advogado, formado pela Faculdade Católica de Salvador. Pós-Graduado em Direito do Trabalho pela Universidade de Coimbra. Mestrando em Direitos Fundamentais e Alteridade pela Universidade Católica do Salvador - Mestrado de Direito da UCSAL. E-mail: rafael.ribeiro.santos@ hotmail.com. Endereço Postal: Condominio Vog Ville Jocky Club, no endereço: Avenida Luis Tarquinio, 926, Centro, Lauro de Freitas-BA. CEP: 42700-130.

* Mestrando em Direitos Alteridade e Direitos Fundamentais, na área de concentração: Políticas públicas e efetivação de direitos fundamentais, pela Universidade Católica do Salvador, advogado, graduado em Direito pela Universidade Católica do Salvador. E-mail: eric.araujo.olveira@gmail.com. Endereço Postal: Condomínio Vilas do Joanes, Rodovia BA-99, Estrada do Coco, Km. 8, Catu de Abrantes, Camaçari- BA.
} 
artigo 791-A a partir da sugestão e estruturação de uma conceituação própria, que é o ponto central da análise a ser desenvolvida.

Não são incomuns decisões judiciais trabalhistas que fazem referência à vulnerabilidade do trabalhador em perspectiva prática, mas são excepcionais aquelas que realmente neutralizam as disparidades perante empregado e empregador. Raros também são os estudos acadêmicos que se dedicam ao tema, com exceções aqui citadas. Assim, é necessário estabelecer os contornos justrabalhistas do conceito de vulnerabilidade, bem como fixar mínima e inicialmente os efeitos de sua aplicação no plano fático.

Para que seja possível trazer a noção de vulnerabilidade para o contexto trabalhista será relevante, de início, traçar seus conceitos em outras ciências, com destaque para a filosofia do Trabalho. Em seguida será necessário fixar distinções entre a vulnerabilidade e os contornos jurídicos da hipossuficiência.

É importante também analisar como o Direito do Trabalho se relaciona com os tipos de vulnerabilidade, consagrados na doutrina, com a busca, sempre que possível, de experiências na realidade fática da prestação laborativa. É relevante também que se pense a vulnerabilidade no contexto do elemento central da relação de emprego.

$\mathrm{O}$ artigo se estrutura em dois eixos. $\mathrm{O}$ desenvolvimento se dará por meio da análise do artigo 791-A sob um prisma mais positivista, deixando de lado quaisquer resquícios da vulnerabilidade, por hora, anteriormente citado.

Com o intuito meramente de abarcar os fundamentos e contraprovas daqueles que julgam o presente texto da CLT benéficos para o cenário do direito do trabalho, como por exemplo, o Ministro Luís Roberto Barroso em seu voto/relato na ação direta de inconstitucionalidade 5.766 distritos federal.

Em segundo momento será analisado minuciosamente o que já fora explicitado, e se estes pressupostos se chocam com a ideia de vulnerabilidade social laboral, buscando entender se de fato existe um aumento ou não da condição de vulnerável/hipossuficiente do empregado perante o empregador.

Pretende-se, então, trazer a ideia de vulnerabilidade para o centro do Direito do Trabalho, afastando qualquer ideia economicamente mais vantajosa ou menos burocrática, principalmente sua aplicação no plano fático, para que se possa ao final tecer uma opinião. 


\section{VULNERABILIDADE SOCIAL E O DIREITO DO TRABALHO}

A priori, se faz imprescindível a explanação do conceito básico de vulnerabilidade e seus derivados (negocial, hierárquica, econômica, técnica, informacional, psíquica e ambiental). Para efeito do presente estudo a conceituação e as distinções relativas ao tema da vulnerabilidade têm aspecto central, pois a partir delas será possível construir compreensões teóricas e práticas também no âmbito do Direito do Trabalho.

Preliminarmente à análise jurídica serão vistos conceitos trazidos pelo léxico e por outros ramos do conhecimento. De início a definição de Houaiss como uma primeira aproximação com a ideia de vulnerável: "ferido, sujeito a ser atacado, derrotado: frágil, prejudicado ou ofendido" (VULNERÁVEL, 2009, p. 1.961).

Resta nítido então que uma pessoa ao estar vulnerável, está sob a eminencia constante ou periódica de sofrer algo, ou estar também à frente de uma grande fragilidade.

Nitidamente este conceito léxico não tem tanta aplicabilidade no contexto laboral, haja vista que o presente estudo não busca analisar relações laborais que resultaram em agressões ou a possíveis lesões. É necessário então entrarmos na perspectiva mais metafisica da relação de vulnerabilidade.

Partindo então deste pressuposto vamos analisar a questão da vulnerabilidade de um ponto mais sociológico e filosófico para podermos entender que, a questão de vulnerabilidade do trabalhador não se restringe intrinsecamente no prisma de lesões e ofensas, mas sim no momento em que o mesmo se encontra na numa relação de trabalho.

De fato, a compreensão de vulnerabilidade em perspectiva jus trabalhista já vem sendo alvo de estudo desde o final do século XX e início do século XXI pela sociologia do trabalho, tal estudo consiste em analisar a precarização do trabalho que é inerente ao capitalismo, às políticas neoliberais, desemprego, desigualdade social e exclusão.

Marcio Pochmann aproxima o conceito de vulnerabilidade com a ideia que poderá ser apresentada ao final do presente estudo:

O distanciamento atual de uma situação de pleno emprego e as mutações nas condições e relações de trabalho e no status do assalariado permitem observar com maior clareza uma ruptura na trajetória de identificação social e de integração comunitária. E, com isso, o surgimento de novas vulnerabilidades sociais no capitalismo torna-se por si só um elemento fundante da exclusão social que se generaliza neste final de século [...] Não parece haver dúvidas, portanto, de que a 
definição de um novo padrão de integração social está ainda por ser desenvolvida. Todavia, é preciso compreender que o Estado necessitaria exercer um papel relevante na luta contra a exclusão social, principalmente no que diz respeito ao enfrentamento do problema do desemprego e das ocupações precárias nas economias avançadas. Sem isso, novas vulnerabilidades sociais tendem a ganhar maior espaço neste final de século (POCHMANN, 1999, p. 11, 23-24).

Sendo assim, tornasse impossível a análise de um conceito de vulnerabilidade sem fugir da ideia de política, pois a vulnerabilidade social vem como estratégia capitalista tendente a fragilizar os antigos modelos de relação capital-trabalho.

Ao invés de vínculos formais, perenes, protegidos e que permitiam uma boa inserção do trabalhador no mercado de consumo, agora as relações são muito mais informais, de curta duração e desprotegidas.

É importante salientar também que o que está sendo discutido no presente estudo não é somente relações unilaterais com prevalência da vulnerabilidade, mais um conglomerado de trabalhadores ou uma nova logica imperiosa imposta por todos os trabalhadores gerando assim uma regulamentação não mais protetiva, mais sim intensificando as fragilidades de toda uma população.

Tudo isso tem uma lógica, que é usufruída as milimétricas gotas por um sistema capitalista e/ou neoliberal. É muito mais maleável manipular um empregado que não é instruído ou que tem medo de seus superiores, ao invés daqueles que estão unidos e protegidos por seus iguais e um Estado sólido, por isso é interessante que estas fragilidades fiquem cada vez mais em evidência para que aqueles, que já detém o poder hierárquico em mãos, possam reinar de forma unilateral em uma relação de trabalho.

Dessa maneira expõe Fabio Tenenblat:

Autores e réus das relações processuais obedecem, em suas formas de agir, a critérios de racionalidade, comuns a diversas áreas do conhecimento. A ponderação entre custos e benefícios no momento de se tomar uma decisão, com vistas à obtenção dos maiores ganhos possíveis, é característica própria do comportamento humano, não sendo diferente no que diz respeito às ações judiciais. (TENENBLAT, Fabio. Limitar o acesso ao poder judiciário para ampliar o acesso à justiça, Revista do Centro de Estudos Judiciários, Brasília, Ano XV, n. 52, jan./mar. 2011, p. 26)

Já é cediço que a ideia de trabalhador vulnerável, comumente utilizado em doutrinas norte-americanas "vulnerable worker", tem uma conotação diminutiva, pois evidentemente o trabalhador se encontra em uma situação de hipossuficiência para com seu empregador (conceito este que iremos tratar em tópico a seguir), o que nos leva ao Art. $7^{\circ}$ da Constituição federal, que delimita as condições mínimas de uma relação de emprego, deixando então 
assuntos extras a comando dos acordos coletivos de trabalho (ACT) e convenção coletiva de trabalho (CCT).

Não obstante disso, é imprescindível levar em consideração que este pressuposto que é consolidado e alicerçado na constituição federal é basilar para todo o regramento internacional, como também preceita Natalia Bentes:

\begin{abstract}
Também, diante da aceitação do princípio da indivisibilidade dos Direitos Humanos consagrado na Conferência Mundial de Viena sobre Direitos Humanos de 1993, houve o alargamento do conceito de obrigação internacional erga omnes no campo dos direitos humanos. Dessa forma, deixa mais evidente o interesse jurídico da comunidade internacional na proteção de todos os direitos humanos internacionalmente reconhecidos, dentre eles, o acesso à justiça, inclusive aos mais vulneráveis.( BENTES, Natalia, apud, FERREIRA, Vanessa, controle de convencionalidade e acesso à justiça: uma análise do beneficiário da justiça gratuita a luz da reforma trabalhista, Revista Videre,Dourados, v. 12,n. 25, 2020, p 12)
\end{abstract}

Ainda nesta linha de pensamento, e visando também proteger os direitos dos mais vulneráveis, a Constituição federal em conjunto com o Estado de direito forneceu então um "peso" para igualar esta balança tão desleal, afastando a ideia de princípios neoliberais intensificadores da vulnerabilidade. De fato, o que rege a carta magna é um norteador das relações de trabalho e amenizador de fragilidades, porem o quem vem à baila neste momento é: Existem ainda regulamentações que possam atenuar esta balança em desfavor do trabalhador? Analisar esta questão é o objeto deste estudo.

\title{
2.1 VULNERABILIDADE E HIPOSSUFICIÊNCIA
}

Claramente a ideia de vulnerabilidade está mais evidente após a explanação alhures, porém para entendemos mais a fundo a ideia no âmbito jus trabalhista se faz necessário não só compararmos, mas também distinguirmos vulnerabilidade e hipossuficiência.

Observando mais na essência da termologia iremos analisar que "hipo" já traz consigo a ideia de inferioridade e uma conotação mais diminutiva, quando conectada com a "suficiência" nos leva a entender que estamos nos referindo a pessoas ou relações nas quais alguém ou algo está em desvantagem perante algo ou alguém.

Em primeira análise seria fácil confundirmos e até acreditar que estas detêm a mesma terminologia ou significado, por isso neste momento irmos explanar sobre o que distingue as duas para depois vislumbrarmos a aplicabilidade e os efeitos destas.

A priori deve-se ter em mente que nem todo trabalhador que é hipossuficiente é vulnerável, mas todo trabalhador, por sua fundamentação na posição contratual de 
empregado, é hipossuficiente. Isto porque a ideia de vulnerabilidade é mais ampla, de maior complexidade do que a de hipossuficiente, e abraça uma maior complexidade de pessoas e problemas.

Ainda nesta linha de pensamento, devemos ter em mente então que todo trabalhador pela simples relação "sine qua non" é hipossuficiente e por esse indiscutível fato exige a construção da regra trabalhista, mas não necessariamente será considerada como relevante no momento de sua interpretação.

Porém a vulnerabilidade não necessariamente fundamenta a construção da norma trabalhista, mas deve ser considerada no momento da sua interpretação e aplicação.

Por mais nebuloso que seja o desmembramento destes conceitos, efetuar essa separação se torna imprescindível para a futura análise desse estudo. Partindo do pressuposto de que todo trabalhador é hipossuficiente, não se faz necessário normas que o regulem, partimos da ideia de que todo o conceito normativo já leva em consideração este princípio basilar.

\begin{abstract}
Partindo da análise etimológica do termo, recuperamos o ensaio das autoras Carmo e Guizard (2018), onde é destrinchada a "vulnerabilidade" a partir do Latim por intermédio das palavras "vulnerare"e "bilis" que, segundo as autoras, representavam uma condição inerente do ser humano, "naturalmente necessitado de ajuda", dispondo sobre os danos potenciais vinculados à mera existência humana, em uma perspectiva individual. Contudo, tal interpretação advinda da origem do termo ainda não consegue dizer sobre a materialidade das vivências humanas, que possuem diversos potenciais atravessadores, como as desvantagens em mobilidade social, cidadania fragilizada, distribuição desigual de políticas públicas, entre outros fatores que compõem a extensão do termo vulnerabilidade em uma perspectiva sóciohistórica.( ALMEIDA, Mateus, apud Carmo e Guizard, Os impactos da vulnerabilidade social na construção da subjetividade, Rev. Psicol Saúde e Debate. Jul., 2021, p 52)
\end{abstract}

Sendo assim, pode então uma regra ou norma respeitar os contornos de hipossuficiência e ainda assim ferir ou atenuar o ideal de vulnerabilidade? Lembre-se que o conceito de vulnerabilidade é ainda mais amplo que o de hipossuficiência e pode abarcar ou não determinada camada de trabalhadores, por isso este conceito nas relações de trabalho podem ser vistas como fundamento de proteção estatal, como justificativa de uma tutela específica e também como instrumento de alargamento da esfera protetiva no direito do trabalho. 
Aqui o conceito de vulnerabilidade entra como uma situação de inferioridade contratual agravada por fatores de riscos ou pela condição pessoal de cada trabalhador, podendo então gerar lesões em suas esferas patrimoniais ou existenciais.

O presente estudo quer levar à baila não só a ideia de defesa de seus interesses laborais, mas sim o que a falta desta proteção ou a diminuição deste pode acarretar na vida social ou existencial de um empregado.

Seguindo este prisma Leandro do Amaral D. de Dorneles explica a importância da noção de vulnerabilidade para o Direito do Trabalho:

A demanda por proteção ao trabalhador, conforme entendemos, ainda é um dado inegável e inquestionável ao direito do trabalho. Mas a definição dos contornos protetivos clássicos do direito do trabalho, ocorrida no início do século passado, tinha por base uma relação então predominante e padronizada - a relação de emprego típica (arts. $2^{\circ}$ e $3^{\circ}$, CLT) - que não se apresenta mais onipresente. Atualmente nem sempre podemos identificar um padrão único de vulnerabilidades (e, consequentemente, uma demanda protetiva uniforme) comum a todos os empregados, da mesma forma que podemos perceber a combinação de diferentes vulnerabilidades em outras relações de trabalho não enquadradas nos contornos dos arts. $2^{\circ}$ e $3^{\circ}$ da CLT. A ideia de vulnerabilidade como fundamento do direito do trabalho tem por intuito aproximar a operacionalidade juslaboral das reais demandas protetivas que se apresentam em um novo mundo do trabalho, reconciliando (ou impedindo o divórcio entre) a instrumentalidade deste ramo jurídico com as reais necessidades sociais, ainda inegavelmente calcadas na demanda protetiva justificada por um desequilíbrio em suas relações jurídicas de base (DORNELES, 2013, p. 296).

\section{STF E ARTIGO 791-A DA CONSOLIDAÇÃO DAS LEIS TRABALHISTAS PÓS REFORMA}

\subsection{PRINCÍPIO DA IRRETROATIVIDADE DAS LEIS E O ARTIGO 791-A}

Já é amplamente discutido por inúmeros profissionais e doutrinadores na área justrabalhista as implicações da reforma trabalhista (Lei ${ }^{\circ}$ 13.467, de 13 de julho de 2017), e seus devidos reflexos no âmbito social dos trabalhadores. No presente estudo iremos somente analisar o artigo 791-A que fora inserido no ordenamento jurídico por advento da reforma em epígrafe.

Art. 791-A. Ao advogado, ainda que atue em causa própria, serão devidos honorários de sucumbência, fixados entre o mínimo de $5 \%$ (cinco por cento) e o 
máximo de $15 \%$ (quinze por cento) sobre o valor que resultar da liquidação da sentença, do proveito econômico obtido ou, não sendo possível mensurá-lo, sobre o valor atualizado da causa $1^{\circ}$ Os honorários são devidos também nas ações contra a Fazenda Pública e nas ações em que a parte estiver assistida ou substituída pelo sindicato de sua categoria§ $2^{\circ}$ Ao fixar os honorários, o juízo observará I - O grau de zelo do profissional II - O lugar de prestação do serviço; III - a natureza e a importância da causa IV - O trabalho realizado pelo advogado e o tempo exigido para o seu serviço§ $3^{\circ} \mathrm{Na}$ hipótese de procedência parcial, o juízo arbitrará honorários de sucumbência recíproca, vedada a compensação entre os honorários§ $4^{\underline{0}}$ Vencido o beneficiário da justiça gratuita, desde que não tenha obtido em juízo, ainda que em outro processo, créditos capazes de suportar a despesa, as obrigações decorrentes de sua sucumbência ficarão sob condição suspensiva de exigibilidade e somente poderão ser executadas se, nos dois anos subsequentes ao trânsito em julgado da decisão que as certificou, o credor demonstrar que deixou de existir a situação de insuficiência de recursos que justificou a concessão de gratuidade, extinguindo-se, passado esse prazo, tais obrigações do beneficiário. $\$ 5^{\circ}$ São devidos honorários de sucumbência na reconvenção

O que impõe saber, num primeiro momento, é se mencionada norma é aplicável a todos os processos, indistintamente; se somente aos ajuizados posteriormente à sua vigência ou apenas aos já sentenciados na vigência dela.

Como é cediço, o atual Código de Processo Civil, aplicável subsidiária e supletivamente ao processo do trabalho (artigos $8^{\circ}$ da CLT), adotou, em seus artigos 14 e 1.046 e em observância ao princípio da irretroatividade das leis (artigo $5^{\circ}, \mathrm{XXXVI}$, da CF), o sistema do isolamento dos atos processuais, de modo que a lei nova, embora aplicável aos processos em andamento, não interfere nos atos processuais já praticados sob a vigência da lei revogada.

No caso dos honorários advocatícios, o respectivo direito da parte vencedora surge com a sentença, na qual é estabelecida a sucumbência e fixada a responsabilidade da parte vencida. Isso sobressai claríssimo da leitura do artigo 85 do Código de Processo Civil, segundo o qual a "sentença condenará o vencido a pagar honorários advocatícios ao advogado do vencedor".

Na mesma senda, mas especificamente a respeito da aplicação da mencionada Lei 13.467/2017, já se pronunciou o Supremo Tribunal Federal, por meio de sua $1^{\text {a }}$ Turma: 
AGRAVO INTERNO. RECURSO EXTRAORDINÁRIO COM AGRAVO. HONORÁRIOS ADVOCATÍCIOS NO PROCESSO DO TRABALHO. ART. 791A DA CONSOLIDAÇÃO DAS LEIS DO TRABALHO, INTRODUZIDO PELA LEI 13.467/2017. INAPLICABILIDADE A PROCESSO JÁ SENTENCIADO. 1. A parte vencedora pede a fixação de honorários advocatícios na causa com base em direito superveniente - a Lei 13.467/2017, que promoveu a cognominada "Reforma Trabalhista". 2. O direito aos honorários advocatícios sucumbenciais surge no instante da prolação da sentença. Se tal crédito não era previsto no ordenamento jurídico nesse momento processual, não cabe sua estipulação com base em lei posterior, sob pena de ofensa ao princípio da irretroatividade da lei. 3. Agravo interno a que se nega provimento. (Ag. Reg. no Recurso Extraordinário com Agravo $\mathrm{n}^{\circ}$ 1.014.675-MG, Rel. Min. Alexandre de Moraes).

Dessa forma, se o processo é sentenciado já na vigência da Lei 13.467/2017, ou seja, a partir de 11 de novembro de 2017, ainda que ajuizado anteriormente, o juiz, independentemente de pedido expresso da parte vencedora (Súmula 256 do STF), haja vista que a norma do artigo 85 do Código de Processo Civil é impositiva "a sentença condenará", deverá condenar a parte vencida ao pagamento da verba honorária, destinada ao advogado ex adverso.

Em detrimento dessa aberração jurídica evidente, se fez imperativo uma instrução normativa do TST de $n^{\circ} 41$, de 21.06.2018 no tocante a inviabilizar esta clara afronta aos interesses laborais, no qual o trabalho agora restaria alvo. A mesma expressa em Art. $6^{\circ}$ :

\footnotetext{
Art. $6^{\circ} \mathrm{Na}$ Justiça do Trabalho, a condenação em honorários advocatícios sucumbenciais, prevista no art. 791-A, e parágrafos, da CLT, será aplicável apenas às ações propostas após 11 de novembro de 2017 (Lei ${ }^{\circ}$ 13.467/2017). Nas ações propostas anteriormente, subsistem as diretrizes do art. 14 da Lei no 5.584/1970 e das Súmulas nº 219 e 329 do TST.
}

Este fato somente corrobora com a ideia de que as medidas adotadas na reforma trabalhistas nem sempre favorecem diretamente o trabalhador, fazendo com que constantes análises se façam necessárias.

\subsection{ARTIGO 791-A E A AÇÃO DIRETA DE INCOSTITUCIONALIDADE}

Já que previamente fora analisado a retroatividade/irretroatividade do artigo em comento, iremos agora mergulhar sobre o conceito constitucional, sob o prisma do voto dado 
por um dos ministros do STF, o Ministro Luís Roberto Barroso, na ação direta de inconstitucionalidade 5.766 distritos federal.

Ementa: DIREITO CONSTITUCIONAL E DO TRABALHO. AÇÃO DIRETA DE INCONSTITUCIONALIDADE. ACESSO À JUSTIÇA. GRATUIDADE DE JUSTIÇA. MÍNIMO EXISTENCIAL. INCONSTITUCIONALIDADE PARCIAL. 1. A Reforma Trabalhista assegurou o direito à gratuidade de justiça aos trabalhadores hipossuficientes, mas determinou: (i) a cobrança de honorários de advogado e de honorários periciais, em caso de sucumbência (CLT, arts. 791-A e 790-B); (ii) a utilização de créditos havidos em outros processos para fazer face a tais honorários (CLT, art. 791-A, $\$ 4^{\circ}$ ); (iii) a cobrança de custas judiciais aos empregados que derem causa ao arquivamento de suas ações por não comparecimento injustificado à audiência (CLT, art. 844, §2 $2^{\circ}$ ). 2. As normas processuais podem e devem criar uma estrutura de incentivos e desincentivos que seja compatível com os limites de litigiosidade que a sociedade comporta. O descasamento entre o custo individual de postular em juízo e o custo social da litigância faz com que o volume de ações siga uma lógica contrária ao interesse público. A sobreutilização do Judiciário congestiona o serviço, compromete a celeridade e a qualidade da prestação da tutela jurisdicional, incentiva demandas oportunistas e prejudica a efetividade e a credibilidade das instituições judiciais. Vale dizer: afeta, em última análise, o próprio direito constitucional de acesso à Justiça. 3. Dessa forma, é constitucional a cobrança de honorários sucumbenciais dos beneficiários da gratuidade de justiça, como mecanismo legítimo de desincentivo ao ajuizamento de demandas ou de pedidos aventureiros. A gratuidade continua a ser assegurada pela não cobrança antecipada de qualquer importância como condição para litigar. O pleito de parcelas indevidas ensejará, contudo, o custeio de honorários ao final, com utilização de créditos havidos no próprio feito ou em outros processos. Razoabilidade e proporcionalidade da exigência. 4. Todavia, em resguardo de valores alimentares e do mínimo existencial, a utilização de créditos havidos em outros processos observará os seguintes critérios: (i) não exceder a 30\% do valor líquido recebido (por aplicação analógica das normas que dispõem sobre desconto em verbas alimentares: Lei 8.213/1991, art. 115, incs. II e VI; Decreto 3.048/1999, art. 154, § $3^{\text {o}}$; e Decreto 8.690/2016, art. $5^{\circ}$ ); e (ii) não incidir sobre valores inferiores ao teto do Regime Geral da Previdência Social (atualmente $\mathrm{R} \$ 5.645,80)$. 5. Também é constitucional a cobrança de custas judiciais dos beneficiários da justiça gratuita que derem ensejo ao arquivamento do feito, em razão do não comparecimento injustificado à audiência. Respeito e consideração à Justiça e à sociedade, que a subsidia. Ônus que pode ser evitado pela apresentação 
de justificativa para a ausência. 6. Por fim, é igualmente constitucional o condicionamento da propositura de nova ação ao pagamento das custas judiciais decorrentes do arquivamento. Medida adequada a promover o objetivo de acesso responsável à Justiça. 7. Interpretação conforme a Constituição dos dispositivos impugnados para assentar, como teses de julgamento: "1. O direito à gratuidade de justiça pode ser regulado de forma a desincentivar a litigância abusiva, inclusive por meio da cobrança de custas e de honorários a seus beneficiários. 2. A cobrança de honorários sucumbenciais poderá incidir: (i) sobre verbas não alimentares, a exemplo de indenizações por danos morais, em sua integralidade; (ii) sobre o percentual de até $30 \%$ do valor que exceder ao teto do Regime Geral de Previdência Social, quando pertinentes a verbas remuneratórias. 3. É legítima a cobrança de custas judiciais, em razão da ausência do reclamante à audiência, mediante sua prévia intimação pessoal para que tenha a oportunidade de justificar o não comparecimento".

Segundo a Reforma Trabalhista o mesmo beneficiário da justiça gratuita, quando sucumbente, deverá arcar com os honorários. Porém no que tange a inconstitucionalidade em epigrafe não há o que se discutir, pois é concebível que todo processo judicial tenha um custo financeiro que precisa ser arcado, e nada mais justo que a parte vencida ou que deu causa ao processo arque com estas, caso vencida.

Mister salientar ainda que no decorrer de todo o trâmite processual o garantidor do acesso judicial gratuito até então, detém suas garantias constitucionais do amplo acesso à justiça sem nenhuma necessidade de adiantar qualquer pagamento. Porém o que se analisa é o fato de que a concessão agora do benefício não implica na isenção total dos valores tributários, mas sim na isenção do adiantamento da verba.

Em breve síntese, o garantidor agora estará somente isento do pagamento adiantado das custas processuais e honorários sucumbenciais até quando perdure a sua situação de miserabilidade, e, enquanto isso não ocorrer, a exigibilidade das obrigações ficarão suspensas.

De fato, levantado o entendimento e questionamentos em epigrafe á pratica, não há (mais uma vez) no que se falar em inconstitucionalidade, visto que de fato caso se perdure a situação de miserabilidade o empregador hipossuficiente ainda estará em gozo de seus benefícios, e também tal medida irá desestimular litigantes de má fé denominados como “aventureiros jurídicos". 
Mister salientar também que o ministro em epigrafe defende a ideia de compensação automática das despesas processuais, ou seja, custas processuais, honorários advocatícios, honorários periciais e etc..., com os créditos recebidos pelo empregado. Subdividindo ainda estes em dois tópicos, verbas de natureza não alimentar (como por exemplo, danos morais), podem ser compensadas na sua integralidade, e verbas de natureza alimentar como salário, hora extra, décimo terceiro e etc..., podem ser compensados no percentual de $30 \%$ do que exceder o teto da previdência.

4. Todavia, em resguardo de valores alimentares e do mínimo existencial, a utilização de créditos havidos em outros processos observará os seguintes critérios: (i) não exceder a 30\% do valor líquido recebido (por aplicação analógica das normas que dispõem sobre desconto em verbas alimentares: Lei 8.213/1991, art. 115, incs. II e VI; Decreto 3.048/1999, art. 154, § 3º e Decreto 8.690/2016, art. $5^{\circ}$ ); e (ii) não incidir sobre valores inferiores ao teto do Regime Geral da Previdência Social (atualmente R \$ 5.645,80).

O que o presente estudo questiona então acerca de inconstitucionalidade, é o "desde que não tenha obtido em juízo, ainda que em outro processo, créditos capazes de suportar a despesa”, contida no $\S 4^{\circ}$ do art. 791-A.

A redação deste dispositivo leva a entender que é legal a compensação e cobrança imediata e automática do beneficiário da justiça gratuita vencida na lide, quanto aos honorários de sucumbência, desde que tenha obtido créditos capazes de suportar a despesa, no mesmo processo ou em outros.

\section{ARTIGO 791-A E O POSSIVEL AUMENTO DA VULNERABILIDADE SOCIAL NO DIREITO DO TRABALHO}

No interim de todo os aspectos vistos no presente estudo a grande indagação que se faz, é se de fato este novo artigo trazido pela reforma iria ou não intensificar a vulnerabilidade dos trabalhadores numa perspectiva social e laboral. De pronto, informo que tal resposta ainda está obscura, levando em consideração todas as contraprovas já suscitadas anteriormente, porém este assunto não pode fugir da baila de discursão e análise.

Já fora explanado a abrangência em que o presente ato normativo abraça, haja vista que até processos em que tiveram seu início posterior a data da promulgação da nova lei, podem sofrer suas implicações. Se, e, somente se, o ato sentencial ocorrer posteriormente à data de 11 de novembro de 2017. 
Já consolidado este entendimento vamos ao ponto em que de fato merece um olhar mais cauteloso o $\S 4^{\circ}$ do art. 791-A. Como também já fora explanado alhures após a leitura da redação deste dispositivo entende-se que, este autoriza a cobrança imediata e automática do beneficiário da justiça gratuita vencido na lide, desde que tenha ele obtido créditos capazes de arcar com as despesas, neste ou em outro processo.

Porém alguns aspectos ainda restam nebulosos sobre esta questão, pois a devida cobrança dos honorários irá depender logicamente da prévia cassação da situação de insuficiência de recursos (o que configura os requisitos básicos do beneficiário da gratuidade da justiça).

Porém a grande problemática do presente artigo se evidencia neste diapasão. Como identificar quando o beneficiário não mais é "miserável”, vulnerável e, portanto, incapaz de arcar com os ônus processuais?

Existe então um caminho lógico que a maioria dos magistrados adotam para fundamentar tal pensamento, primeiro o credor deve demonstrar que o vencido não mais se encontra na situação de insuficiência de recursos, segunda, o próprio magistrado pode efetuar uma análise e perceber de oficio que o vencido não mais é detentor do conceito de "miserável" e a terceira, à luz no mesmo artigo em epigrafe é que esta comprovação não pode extrapolar o prazo prescricional de dois anos.

Numa análise nua e crua entendesse que a concessão do benefício da gratuidade da justiça está entrelaçada com a constante comprovação de insuficiências financeiras para com a lide em questão. Porém se faz necessário neste momento não uma perquirição meramente literal, mas sim uma análise mais voltada para a prática em si.

Nítida então a celeuma na qual o trabalhador se encontra, como se perfaz na prática o desaparecimento da situação de insuficiência de recursos?

Em uma situação hipotética, que melhor ajudará a elucidar a questão, o trabalhador por advento de uma situação alheia a sua percepção inicial, venha a adquirir uma grande quantia em dinheiro, $\mathrm{R} \$ 20.000,00$ (vinte mil reais), oriunda ou de uma herança ou de quitação de uma dívida, as hipóteses são infinitas, este então, após a percepção da quantia se torna capaz de arcar com os ônus do processo vencido? 
Vamos mais além, suponha agora quem em determinado processo trabalhista em que o trabalhador efetua 5 (cinco) pedidos dos quais, após a sentença obtém êxito em somente dois dos mesmos, o que geraria uma sentença parcialmente procedente.

Ainda neste caso hipotético suponha ainda que nesta lide a somatória dos valores líquidos perfaz a quantia de $\mathrm{R} \$ 80.000,00$ (oitenta mil reais) e que também seja condenado em honorários sucumbenciais ao pagamento de $\mathrm{R} \$ 10.000,00$ (dez mil reais).

A luz da capacidade fomentada do $\S 4^{\circ}$ do art. 791-A o magistrado tem a capacidade de entender que desapareceu a insuficiência de recursos, por hora proferida, e por consequência disto, revogar o benefício da gratuidade e determinar a imediata compensação dos honorários de sucumbência do crédito do trabalhador.

Há ainda quem defenda a ideia de que os créditos trabalhistas têm natureza alimentar, não existindo assim a possibilidade de compensação. A interpretação literal dos arts. 100, § $1^{\circ}$, da CF, 23 e 24 da Lei n. 8.906/1994, e 823, IV, do CPC, deixa claro o caráter alimentar dos honorários sucumbenciais.

Ainda, o art.85, § 14, do CPC (12) disciplina, expressamente, que os honorários têm natureza alimentar, com os mesmos privilégios dos créditos oriundos da legislação do trabalho. No âmbito da jurisprudência o STF pacificou a questão, quando editou a Súmula Vinculante n. 47:

Os honorários advocatícios incluídos na condenação ou destacados do montante principal devido ao credor consubstanciam verba de natureza alimentar cuja satisfação ocorrera com a expedição de precatório ou requisição de pequeno valor, observada ordem especial restrita aos créditos dessa natureza.

Sendo assim, diante do caráter alimentar dos honorários de sucumbência, não existem dúvidas no que tange a compensação nos próprios autos. Dado o caráter alimentar dos honorários advocatícios, o STJ regula:

PROCESSO CIVIL. CIVIL. ACAO DE ALIMENTOS.HONORARIOS ADVOCATICIOS SUCUMBENCIAIS.CARATER ALIMENTAR. EXECUCAO. PENHORA DOS VENCIMENTOS DO EXECUTADO. POSSIBILIDADE. Os honorários advocatícios constituem direito do advogado e tem natureza alimentar, não havendo óbice para que sua execução seja realizada mediante constrição de parcela dos vencimentos do devedor, desde que não comprometa a subsistência 
deste. Inteligência dos arts. $85, \S 14$, e 833 , inciso IV, e $\S 2^{\circ}$, todos do Código de Processo Civil (TJ-DF 20130210028360 - Segredo de Justiça 000278858.2013.8.07.0002, Relator. ESDRAS NEVES, Data de Julgamento: 05.07.2017, $6^{\mathrm{a}}$ TURMA CIVEL, Data de Publicação: Publicado no DJE: 11.07.2017. p. 371-393); DIREITO CIVIL E PROCESSUAL CIVIL. EXECUCAO. HONORARIOS ADVOCATICIOS. NATUREZA ALIMENTAR, MESMO QUANDO SE TRATAR DE VERBAS DE SUCUMBENCIA.PRECEDENTES DA CORTE ESPECIAL E DO SUPREMO TRIBUNAL FEDERAL. COLISAO ENTRE O DIREITO A ALIMENTOS DO CREDOR E O DIREITO DE MESMA NATUREZA DO DEVEDOR. 1. Honorários advocatícios, sejam contratuais, sejam sucumbenciais, possuem natureza alimentar. (EREsp 706331/PR, Rel. Ministro HUMBERTO GOMES DE BARROS, Corte Especial, DJe 31.03.2008). 2. Mostrando- se infrutífera a busca por bens a serem penhorados e dada a natureza de prestação alimentícia do credito do exequente, de rigor admitir o desconto em folha de pagamento do devedor, solução que, ademais, observa a gradação do art. 655 do CPC, sem impedimento da impenhorabilidade constatada do art. 649, IV, do CPC. 3.- Recurso Especial provido (STJ - REsp: 948492 ES 2007/0103337-5, Relator: Ministro SIDNEI BENETI, Data de Julgamento: 01.12.2011, T3 - TERCEIRA TURMA.

\section{CONCLUSÃO}

Como já fora explicitado anteriormente não cabe ao escopo do presente artigo questionar ou não a inconstitucionalidade do presente artigo, mas sim realizar uma análise se este está agravando a condição de vulnerabilidade do trabalhador.

Partindo do pressuposto de que todo trabalhador por si só, já é hipossuficiente, resta somente o conceito de vulnerabilidade para proteger o que a doutrina pontua como Dignidade da Pessoa humana, na celeuma jus trabalhista.

A ideia de vulnerabilidade aqui vem com a intenção metafísica de promover uma igualdade ainda maior na balança laboral, atenuando a diferença entre empregado e empregador. O problema surge quando determinado ato vai de encontro com este princípio basilar e acaba por aumentar este distanciamento.

Logicamente o artigo 791-A é um grande divisor de águas na justiça do trabalho, assim como inúmeros outros que abarcam o conglomerado de artigos da reforma trabalhista, porém se torna inaceitável e até aversivo que tais, vão de encontro com todos os princípios edificantes da ordem social e tornem a vida do trabalhador ainda mais tortuosa. 
A constante necessidade de comprovação de insuficiências financeiras para com a lide faz uma cabal referência ao mito da espada de Dâmocles, que teve a oportunidade de gozar de todos os luxos oferecidos pelo rei, porém teve a todo tempo uma espada afiada pendurada somente por um fio de rabo de cavalo sobre sua cabeça, fazendo com que Dâmocles, logo perdesse o interesse pelas excelentes comidas e pelas belas garotas, sob a grande ameaça de a qualquer tempo ou infortúnio, ser atingido pelo objeto que, mesmo não oferecendo perigo eminente, poderia lhe desferir o golpe mortal.

Ou seja, trazendo para o contexto desta pesquisa, vincular o trabalhador durante o prazo prescricional de dois anos sob a constante necessidade de comprovação de insuficiência financeira, poderia lhe acarretar prejuízos na esfera psicológica ao ponto de desestimular o mesmo a quiçá pleitear seus direitos na seara trabalhista.

\section{REFERENCIAS:}

ALMEIDA, Mateus, apud Carmo e Guizard, Os impactos da vulnerabilidade social na construção da subjetividade, Rev. Psicol Saúde e Debate. Jul., 2021, p 52

BRASIL. Ação Direta De Inconstitucionalidade 5.766 Distrito Federal. MIM. Luís Roberto Barroso. Disponível em: < eextension://efaidnbmnnnibpcajpcglclefindmkaj/viewer.html?pdfurl=https $\% 3 \mathrm{~A} \% 2 \mathrm{~F} \% 2 \mathrm{Fwww}$. conjur.com.br\%2Fdl\%2Fvoto-fachin-reforma-trabalhista.pdf\&clen=167264\&chunk=true>

BRASIL. LEI No 13.467, DE 13 DE JULHO DE 2017. Altera a Consolidação das Leis do Trabalho (CLT), aprovada pelo Decreto-Lei $\mathrm{n}^{\circ} 5.452$, de $1^{\circ}$ de maio de 1943 , e as Leis $\mathrm{n}^{\circ} 6.019$, de 3 de janeiro de 1974, 8.036, de 11 de maio de 1990, e 8.212, de 24 de julho de 1991, a fim de adequar a legislação às novas relações de trabalho. Disponível em <http://www.planalto.gov.br/ccivil_03/_ato2015-2018/2017/lei/113467.htm>

BRASIL. Recurso Extraordinário com Agravo no 1.014.675-MG.Rel. Min. Alexandre de Moraes. Disponível em: <https://www.jusbrasil.com.br/processos/137275024/processo-n1014675-do-stf>.

BRASIL. Lei No 8.906, De 4 De Julho De 1994. Dispõe sobre o Estatuto da Advocacia e a Ordem dos Advogados do Brasil (OAB). disponivel em

<http://www.planalto.gov.br/ccivil_03/leis/18906.htm\#: :text=LEI\%20N\%C2\%BA\%208.906 \%2C\%20DE\% 204\%20DE\%20JULHO\%20DE\%201994.\&text=Disp\%C3\%B5e\%20sobre\%2 0o\%20Estatuto\%20da,Advogados\%20do\%20Brasi1\%20(OAB).\&text=II\%20\%2D\%20as\%20 atividades $\% 20 \mathrm{de} \% 20$ consultoria $\% 2 \mathrm{C} \% 20$ assessoria $\% 20 \mathrm{e} \% 20 \mathrm{dire} \% \mathrm{C} 3 \% \mathrm{~A} 7 \% \mathrm{C} 3 \% \mathrm{~A} 3 \mathrm{o} \% 20 \mathrm{j}$ ur $\% \mathrm{C} 3 \%$ ADdicas. \&text $=\% \mathrm{C} 2 \% \mathrm{~A} 7 \% 203 \% \mathrm{C} 2 \% \mathrm{BA} \% 20 \mathrm{No} \% 20 \mathrm{exerc} \% \mathrm{C} 3 \% \mathrm{ADcio} \% 20 \mathrm{da}, \mathrm{ma}$ nifesta\%C3\%A7\%C3\%B5es\%2C\%20nos\%20limites\%20desta\%20lei>. 
BENTES, Natalia, apud, FERREIRA, Vanessa, Controle de convencionalidade e acesso à justiça: uma análise do beneficiário da justiça gratuita a luz da reforma trabalhista, Revista Videre,Dourados, v. 12,n. 25, 2020, p 12

DORNELES, Leandro do Amaral D. de. Hipossuficiência e Vulnerabilidade na Teoria Geral do Direito do Trabalho Contemporânea. Revista LTr., ano 77, março de 2013. São Paulo: LTr., 2013.

POCHMANN, Márcio. Trabalho sob Fogo Cruzado: exclusão, desemprego e precarização no final do século. São Paulo: Contexto, 1999.

VULNERÁVEL. In: HOUAISS, Antônio; VILLAR, Mauro de Salles; FRANCO, Francisco Manoel de Melo. Dicionário Houaiss da língua portuguesa. 1. ed. Rio de Janeiro: Objetiva, 2009.

TENENBLAT, Fabio. Limitar o acesso ao poder judiciário para ampliar o acesso à justiça, Revista do Centro de Estudos Judiciários, Brasília, Ano XV, n. 52, jan./mar. 2011, P. 26) 